\title{
Gunshot Injuries Involving Musculo-Skeletal System at the Federal Medical Centre,
}

Lagos

\section{AA Dada \\ BO Awoyomi}

Department of Orthopaedics and Trauma,

Federal Medical Center, Ebute-Metta, Lagos, Nigeria

\author{
All Correspondence: \\ Dr. AA Dada \\ Department of Orthopaedics \\ and Trauma, \\ Federal Medical Center, \\ Ebute-Metta, Lagos, Nigeria \\ E-mail: \\ dadajuwon@yahoo.com
}

\author{
Abstract \\ Background \\ Gunshot injury (GSI) is a common cause of morbidity and mortality in Nigeria. \\ It is important to study the circumstances and type of injuries for policy \\ formulation to reduce its occurrence.
}

\section{Objective}

This is to study the demographic profile of GSI patients to assist policy design and reduce its incidence in Nigeria.

\section{Method \\ This is a two year prospective study of the pattern of GSI to the musculoskeletal system using observer administered questionnaires at a tertiary health centre in Lagos, Nigeria and a review of the outcome of the treatment of these injuries.}

\section{Results}

Fifty four patients with gunshot injury to the musculoskeletal system were studied accounting for $(10.3 \%)$ of the five hundred and twenty four (524) patients with musculoskeletal injuries treated in the hospital during the period under study.

The peak incidence was in the age group 21-30 years and 41-50 years. The limbs $(84.1 \%)$ were the most affected parts of the body. Policemen $(42.6 \%)$ and traders $(28.9 \%)$ were the most commonly affected people. Violent crime accounted for $85.2 \%$ of GSI; Low velocity rifles were the commonest weapon of assault $(59.3 \%)$. Unfortunately a large number of the patients $(44.4 \%)$ declined orthodox treatment opting for traditional care. Unintentional shooting occurred in only $11.1 \%$ of cases.

\section{Conclusion}

Majority of GSI occurred in male young people especially policemen and traders. The need for local businessmen to use "cashless" transfer of funds needs to be emphasized. Law enforcement officers need more training and better equipment to effectively confront criminal elements.

Key Words: Gunshot injury, musculo-skeletal system

\section{Introduction}

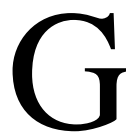
unshot injuries are major causes of causes of morbidity and mortality in Nigeria. Majority of GSI are from violent crimes. High incidence of violent crimes apart from being of public health importance can also adversely affect the economy of a country. Indeed, it is a vicious circle in which a poor economy and the consequent low employment opportunities encourage violent crimes.

Furthermore, gunshot injuries is an important cause of mortality in Nigeria and this is reported as $5-25 \%$ in some studies. In addition, the treatment of survivors is often associated with complications ${ }^{1-4}$.
In Nigeria, there is poor health insurance cover for the population and over $80 \%$ of the payment for hospital care is still funded, using "the out of pocket payment method" it is therefore not surprising that complications as a sequelae of treatment is still high because most of the required surgical procedures are done only when payment has been made. Because of the challenges in the management of these patients, emphasis need to be placed on preventive strategies among the vulnerable group ${ }^{5,6}$

\section{Patients and Methods}

This study took place at the Federal Medical Centre Ebute-Metta, Lagos, Nigeria which is a tertiary health care centre. It receives referrals from both private 
hospitals and secondary care centers in Lagos and sometime beyond. It has both inpatient and outpatient facilities with a well developed trauma unit.

This is a prospective study of all cases of musculoskeletal gunshot injuries that presented from $1^{\text {st }}$ October 2006 to $30^{\text {th }}$ September 2008 who were treated in the unit.

After obtaining the ethics committee approval and the consent of the patients, questionnaire were administered on all the patients who presented with gunshot injuries during the study period and the following information were obtained biodata, source of injury, anatomical site of injury, time of injury and presentation. The patients were interviewed and examined to determine the type of firearm used and the nature of injuries sustained. They were also followed-up to identify complications (if any), duration of hospital stay and the outcome of treatment.

\section{Results}

A total of 54 patients were studied, and the age of the patients ranged from 21-60 years with the highest incidence being in the 21-30 year of age group which accounted for 20 patients (37\%) followed by the age group 41-50 which accounted for 16 patients $(29.6 \%)$.

Table 1: Age Distribution

\begin{tabular}{lll}
\hline Age & Frequency & \% \\
\hline $0-10$ & - & - \\
$11-20$ & - & - \\
$21-30$ & 20 & 37.0 \\
$31-40$ & 13 & 24.1 \\
$41-50$ & 16 & 29.6 \\
$51-60$ & 5 & 9.3 \\
\hline
\end{tabular}

Males accounted for fifty patients $(92.6 \%$ and female for four patients $(7.4 \%)$ giving a ratio of 12.5:1. Whereas 34 patients $(63 \%)$ sustained only soft tissue injury, 20 patients (37\%) had associated bony injuries.

There were twenty-eight patients with lower limb injuries $(51.9 \%)$ and twenty patients with upper limb injuries $(37 \%)$ while three patients $(5.6 \%)$ each had injuries involving the head and neck and the chest.

Armed robbers were responsible for the injuries in 46 cases $(85.2 \%)$ whereas, accidental discharge from the police were the cause in six cases $(11 \%)$, three of the accidental discharges involved police to police accidental discharge and another three were police to civilian accidental discharge. The source of injury could not be identified in two cases.
Twenty three of the patients $(42.6 \%)$ were policemen while twenty-one patients $(38.9 \%)$ were traders with eighteen of the traders $(85.7 \%)$ admitting to carrying large sums of money at the time attack. Civil servants $(7.4 \%)$, drivers $(5.6 \%)$, artisans $(3.7 \%)$ and retired workers(1.9\%) accounted for the other patients in the series.

Low velocity rifles were the weapon of assault in thirty cases $(55.6 \%)$ and high velocity rifle in six cases $(11.1 \%)$. The type of firearm used could not be determined in the remaining eighteen patients (33.3\%). All patients were offered hospital admission to enable immediate debridement; however twenty patients (37\%) declined admission. Fourteen patients (25.9\%) took voluntary discharge after initially accepting admission and undergoing resuscitation and debridement. Therefore only 20 patients (37\%) completed treatment.

The duration of hospital stay for the thirty-four patients who were admitted as seen in table 2 .

Table 2: Duration of Hospital Stay.

\begin{tabular}{lll}
\hline Duration & Frequency & \% \\
\hline Declined admission & 20 & $37 \%$ \\
0 - 2 weeks & 16 & 29.6 \\
- 4 weeks & 8 & 14.8 \\
4 - 6 weeks & 3 & 5.6 \\
6 - 8 weeks & 1 & 1.9 \\
> w weeks & 6 & 11.1 \\
\hline
\end{tabular}

The complications seen in the twenty patients who completed treatment were wound infection in six $(30 \%)$ and chronic osteomyelitis in one patient (5\%). Though two patients had nerve damage at presentation both of them had full functional recovery during treatment.

\section{Discussion}

With an unstable national economy and attendant increase in unemployment in Nigeria, the incidence of gunshot injuries appear to be reaching epidemic proportion. $^{1-5}$ In this study, the victims were mainly policemen $(42.6 \%)$ or traders $(38.9 \%)$ and they were in the $3^{\text {rd }}, 4^{\text {th }}$ and $5^{\text {th }}$ decade of life. The reason for the predominance of policemen is due to the frequent confrontations between policemen and robbers in the course of policing duties. On the other hand, local traders because they carry large amounts of cash on their persons are usual targets of robbers. $85.7 \%$ of the traders admit to carrying substantial sums of money at the time of the attack. This high rate probably suggests the presence of an effective intelligence network by the criminals. Indeed, the way petty trades are organized in Nigeria gives credence to this assertion as majority of the traders usually have one or more assistants who are either not paid or poorly paid and 
therefore prone to financial inducement.

Violent crime continue to be the leading cause of GSI in our environment and the fact that $85.5 \%$ of the injuries in this series were actually sustained from armed robbers is a pointer to the enormity of the problem. This is further reinforced by findings from other studies in Nigeria $^{5-7}$. Furthermore, findings from this study shows that law enforcement officers are as vulnerable to attacks from criminals as are the civilian population they are paid to protect. This calls for a review of the rules of engagement of our policemen and the calibre of weapons available to them for their duties and of course the training programmes of the police.

The study shows that a majority $(55.6 \%)$ of the weapons available to the armed robbers are low caliber weapons. This is also similar to the finding by Solagberu in Ilorin $^{2}$ where he found that only $20.3 \%$ of his series were injuries caused by high velocity weapons...Afuwape and Alonge in Ibadan also showed a predominance of low velocity weapons in their series ${ }^{8}$. It is therefore not surprising that majority of the injuries $(63 \%)$ in our series were soft tissue injuries since the weapon used mostly were low velocity guns. Furthermore, $88.9 \%$ of the injuries in this series and the majority in other series ${ }^{5,8,9}$ affected the extremities, perhaps a pointer to the intention of the assailants to maim rather than kill. However, this may not be the complete picture as patients with injuries to the abdomen were excluded from this study.

The low number of patients who completed treatment is not surprising because of the belief in our environment on the efficacy of traditional care and the need to extract bullets traditionally ${ }^{10}$. Majority of those who declined orthodox treatment ended up in traditional care centers.

A major drawback in our health care system is the prerequisite of most hospitals to insist on payment for services particularly after the initial resuscitation. The consequence of this, particularly in trauma care is unnecessary delays in the institution of definitive care .Wound infections occurred in $20 \%$ of the treated case in this series. This high figure is comparable to that seen in other studies in this environment ${ }^{1,2}$. The reason for this is not far-fetched from delays in instituting debridement due to financial reasons and the usual problems of patients not buying their drugs after surgery.

It is therefore obvious from the results of this study that the financial sector needs some re-engineering to ensure that those in the informal sector of the economy are able to confidently transfer funds and make payments in a cashless manner.

Findings from Nairobi and Durban ${ }^{9,11}$ appear to follow similar demographic pattern when compared to Nigeria in terms of age, sex and affected part of the body.

\section{Conclusion}

Violent crime still account for a vast majority of the reasons for Gunshot Injuries in our environment and the civilian victims are usually local traders who transfer large amounts of money and policemen whose duty it is to prevent crime. Most of the injuries are to the limb and the usual weapons of assault are low velocity firearms. Our country need to evolve a safe and reliable cashless payment system and also ensure better support for the law enforcement officers to prevent crimes with minimal collateral damage, while ensuring that victims of crimes are fully cared for without any bottlenecks.

\section{References}

1. Obalum DC, Giwa SO. Outcome of extremity gunshot injuries at Lagos University Teaching Hospital, Lagos, Nigeria; Niger Med. 2007; 48: 14-16.

2. Solagberu BA. Epidemiology and Outcome of Gunshot Injuries in a Civilian Population in West Africa; 2003; 29:92-4.

3. Yinusa W, Ogirima MO. Extremity Gunshot Injuries in Civilian Practice: The National Orthopaedic Hospital, Igbobi experience; West African J Med. 2000; 19(4): 312 -6.

4. Obalum DC, Giwa SO, Ogo CN. Pattern of extremity gunshot injuries seen Lagos University Teaching Hospital, Lagos, Nigeria. Nig. Q J Hosp. 2007; 17(4): 140 -3.

5. Onumiya JE, Ohwowhiagbese E. Pattern of Civilian Gunshot Injuries in Irrua Nigeria. S Afr J Surg. 2005, 43(4): 170-2.

6. Udosen AM, Etiuma AU, Ugara GA, et al. Gunshot Injuries in Calabar, Nigeria: an indication of increasing societal violence and police brutality. Afr Health Sci. 2006: 6(3): 170-2.

7. Katchy AO. Gunshot Wound of the extremities: A review of 57 cases. Orient J. Med 1992; 2:216-8.

8. Afuwape $\mathrm{O}$, Alonge $\mathrm{T}$. An audit of gunshot injuries seen in the accident and emergencies department of a Nigerian tertiary hospital. West Afr J med 2006;25(4):395-7.

9. Saidi HS, Nyakiamo J, Faye S. Gunshot injuries as seen at the Aga Khan Hospital, Nairobi, Kenya .East Afr med J 2002,79(4);188-929.

10. Thanni LOA. Factors influencing patronage of traditional bonesetters. West Afr J Med 2000;19(3):220-224.

11. Agbejule OA, Jonbert G, Botha JB, Van Vuuren MV. Gunshot injured patients at Prince Mshigeri Memorial Hospital, Durban-Profile and Outcome. S Afr med J.2002;92(3):212. 